\title{
Incidence of Macrosomia in Rural Areas - Henan Province, China, 2013-2017
}

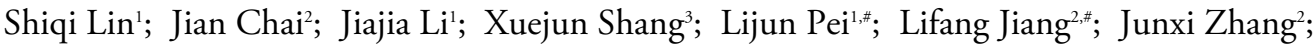 \\ Panpan Sun'; Wei Dong'; Yuhong Wang'; Dezhuan Zhou ${ }^{2}$
}

\section{ABSTRACT}

Introduction: Macrosomia has short-term and long-term adverse health effects and is thus an important public health concern. Recent decades have witnessed increasing incidence of macrosomia in many countries.

Methods: The present study used a large population-based birth cohort study to depict incidence of macrosomia among live births in rural areas of Henan Province of China from 2013 to 2017.

Results: Among the 1,262,916 births, 82,353 were cases of macrosomia. The overall incidence of all types of macrosomia, of macrosomia with birth weight $<4,500 \mathrm{~g}$, and of macrosomia with birth weight $\geq 4,500 \mathrm{~g}$ were $6.52 \%, 5.30 \%$, and $1.22 \%$, respectively. From 2013 to 2017 , the incidence of macrosomia decreased by $31.3 \%$ from $7.96 \%$ in 2013 to $5.47 \%$ in 2017 $\left(\chi_{\text {trend }}^{2}=946.96, P_{\text {trend }}<0.001\right)$. Male infants and infants $\geq 42$ gestational weeks had significantly higher incidence of macrosomia than that of female infants and infants $<42$ gestational weeks $(P<0.001)$.

Conclusion: Gestational weight control through nutrition management and physical activities during pregnancy are needed to reduce incidence of macrosomia.

\section{INTRODUCTION}

Macrosomia refers to livebirths with birth weight $\geq 4,000 \mathrm{~g}$ and is an important public health concern. A wealth of evidence has indicated that macrosomia is associated with risk of infant and maternal complications and long-term morbidities in infants (1), which carries emotional and economic costs to families and society. Recent decades witnessed rising trends in incidence of macrosomia in many developing countries (2). Due to lack of a national vital statistics system with detailed information on birth indicators, China's secular and temporal changes in macrosomia incidence were unclear, with large variations across years and regions in different reports (3-4). Earlier research has found significant differences in macrosomia incidence between urban and rural areas (5), yet most studies were mainly based on hospital data in urban areas, especially in southern or northern regions. Henan, located in central China, was among the largest populated and agricultural provinces in China with over 109 million people, while its incidence of adverse pregnancy outcomes including macrosomia was scarcely reported. The aim of the present study was to use a large population-based birth cohort study to depict the incidence of the macrosomia among live births in rural areas of Henan Province of China from 2013 to 2017.

\section{METHODS}

The study data came from the National Free PrePregnancy Check-Up Project (NFPCP) in Henan Province. The NFPCP has been providing free health examinations and counselling services for couples intending to become pregnant, especially in rural areas, and following up with pregnancy outcomes since 2010 . Basic sociodemographic information of participants, including maternal age and educational level were collected at baseline. Healthcare workers then interviewed women face-to-face or by telephone from beginning of pregnancy to delievery or termination of pregnancy, recording their pregnancy outcomes (normal birth, miscarriage, induced abortion, or stillbirth, etc.), delivery date, gestational weeks, and newborn information (gender and birth weight, etc.) Detailed design of the project was described elsewhere (6). A total of 1,262,916 pregnant women delivered live births in 2013-2017 and were thus included in our analysis. The study protocol was reviewed and approved by Ethics Committee of Henan Institute of Reproductive Health Science and Technology, and written informed consent was obtained from all participants.

Birth indicators were measured by trained obstetricians. Macrosomia was defined as live births 
with $\geq 4,000 \mathrm{~g}$ birth weight. Subgroups of macrosomia were also analysed, including term macrosomia (gestational weeks $\geq 37$ and $<42$ ), post-term macrosomia ( $\geq 42$ gestational weeks), macrosomia with birth weight $<4,500 \mathrm{~g}$, and macrosomia with birth weight $\geq 4,500 \mathrm{~g}$. The incidence of macrosomia was calculated by using total number of macrosomia as the numerators and all live births as the denominators. We used chi-squared tests to compare incidence (denoted as $\chi^{2}$ ) and chi-squared trend tests to examine the trends of incidence across years (denoted as $\chi_{\text {trend }}^{2}$ ). The significance level of tests was $<0.05$. $R$ software (version 4.0.2, R Development Core Team, Vienna, Austria) was used for the analysis.

\section{RESULTS}

Among the 1,262,916 births, 82,353 were cases of macrosomia (Table 1). The total incidence of macrosomia was $6.52 \%$. The incidence of macrosomia

TABLE 1. Incidence of macrosomia in rural areas of Henan Province from 2013 to 2017.

\begin{tabular}{|c|c|c|c|c|c|c|c|}
\hline \multirow{3}{*}{ Item } & \multirow{3}{*}{$\begin{array}{c}\text { Births } \\
\text { n }\end{array}$} & \multicolumn{6}{|c|}{ Macrosomia } \\
\hline & & \multicolumn{2}{|c|}{ Total } & \multicolumn{2}{|c|}{$<4,500 \mathrm{~g}$} & \multicolumn{2}{|c|}{$\geq 4,500 \mathrm{~g}$} \\
\hline & & $\mathbf{n}$ & Incidence, \% & $\mathbf{n}$ & Incidence, \% & $\mathbf{n}$ & Incidence, \% \\
\hline Total & $1,262,916$ & 82,353 & 6.52 & 66,988 & 5.30 & 15,365 & 1.22 \\
\hline \multicolumn{8}{|l|}{ Year } \\
\hline $2013^{*}$ & 56,816 & 4,524 & 7.96 & 3,615 & 6.36 & 909 & 4.60 \\
\hline 2014 & 314,403 & 22,142 & 7.04 & 17,771 & 5.65 & 4,371 & 1.39 \\
\hline 2015 & 320,878 & 22,638 & 7.06 & 18,782 & 5.85 & 3,856 & 1.20 \\
\hline 2016 & 333,564 & 20,061 & 6.01 & 16,322 & 4.89 & 3,739 & 1.12 \\
\hline 2017 & 237,255 & 12,988 & 5.47 & 10,498 & 4.42 & 2,490 & 1.05 \\
\hline$P_{\text {trend }}$ & & & $<0.001$ & & $<0.001$ & & $<0.001$ \\
\hline \multicolumn{8}{|l|}{ Maternal age (years) } \\
\hline $15-19$ & 12,364 & 781 & 6.32 & 644 & 5.21 & 137 & 1.11 \\
\hline $20-24$ & 385,873 & 26,190 & 6.79 & 21,448 & 5.56 & 4,742 & 1.23 \\
\hline $25-29$ & 628,185 & 40,620 & 6.47 & 33,013 & 5.26 & 7,607 & 1.21 \\
\hline $30-34$ & 168,905 & 10,656 & 6.31 & 8,578 & 5.08 & 2,078 & 1.23 \\
\hline $35-39$ & 52,306 & 3,157 & 6.04 & 2,528 & 4.83 & 629 & 1.20 \\
\hline $40-49$ & 14,807 & 916 & 6.19 & 750 & 5.07 & 166 & 1.12 \\
\hline$P$ & & & $<0.001$ & & $<0.001$ & & 0.648 \\
\hline \multicolumn{8}{|l|}{ Maternal education } \\
\hline College and above & 104,252 & 7,319 & 7.02 & 5,703 & 5.47 & 1,616 & 1.55 \\
\hline Senior high school & 196,481 & 13,144 & 6.69 & 10,676 & 5.43 & 2,468 & 1.26 \\
\hline Junior high school & 918,954 & 58,779 & 6.40 & 48,155 & 5.24 & 10,624 & 1.16 \\
\hline Primary school and below & 11,368 & 718 & 6.32 & 574 & 5.05 & 144 & 1.27 \\
\hline$P$ & & & $<0.001$ & & $<0.001$ & & $<0.001$ \\
\hline \multicolumn{8}{|l|}{ Gender } \\
\hline Male & 645,042 & 56,079 & 8.69 & 46,753 & 7.25 & 9,326 & 1.45 \\
\hline Female & 621,982 & 26,211 & 4.21 & 20,187 & 3.25 & 6,024 & 0.97 \\
\hline$P$ & & & $<0.001$ & & $<0.001$ & & $<0.001$ \\
\hline \multicolumn{8}{|l|}{ Gestational weeks } \\
\hline$<41$ & $1,195,938$ & 75,652 & 6.33 & 61,596 & 5.15 & 9,326 & 0.78 \\
\hline$\geq 42$ & 66,978 & 6,701 & 10.0 & 5,392 & 8.05 & 6,024 & 8.99 \\
\hline$P$ & & & $<0.001$ & & $<0.001$ & & $<0.001$ \\
\hline
\end{tabular}

* Only part of study areas were included. 
with birth weight $<4,500 \mathrm{~g}$ and macrosomia with birth weight $\geq 4,500 \mathrm{~g}$ were $5.30 \%$ and $1.22 \%$, respectively. Male infants have significantly higher incidence of macrosomia than that of female infants regardless of birth weight $(P<0.001)$. Incidence of macrosomia with $\geq 42$ gestational weeks was much higher than that of $<42$ gestational weeks regardless of birth weight $(P<0.001)$. Figure 1 showed the incidence trend of macrosomia from 2013 to 2017 . The incidence of total macrosomia decreased by $31.28 \%$ overall from $7.96 \%$ in 2013 to $5.47 \%$ in $2017 \quad\left(\chi_{\text {trend }}^{2}=946.96\right.$, $\left.P_{\text {trend }}<0.001\right)$. The term macrosomia subgroup also showed similar decreases, yet post-term macrosomia rose from $0.27 \%$ in 2013 to $0.60 \%$ in 2015 and dropped to $0.45 \%$ in $2017\left(\chi_{\text {trend }}^{2}=4.64, P_{\text {trend }}<0.05\right)$.

Figure 2 showed incidence of macrosomia subgroups by maternal age. The incidence of macrosomia $<4,500 \mathrm{~g}$ increased from age $15-19(5.21 \%)$ to age $20-24$ $(5.56 \%)$, decreasing afterwards until age 35-39 $(4.83 \%)$ and then increasing slightly at age 40-49 (5.07\%, $\left.\quad \chi^{2}=94.73, \quad P<0.001\right)$. There was no significant changes in incidence of macrosomia with $\geq$ $4,500 \mathrm{~g}$ by maternal age $\left(\chi^{2}=3.34, P=0.648\right)$.

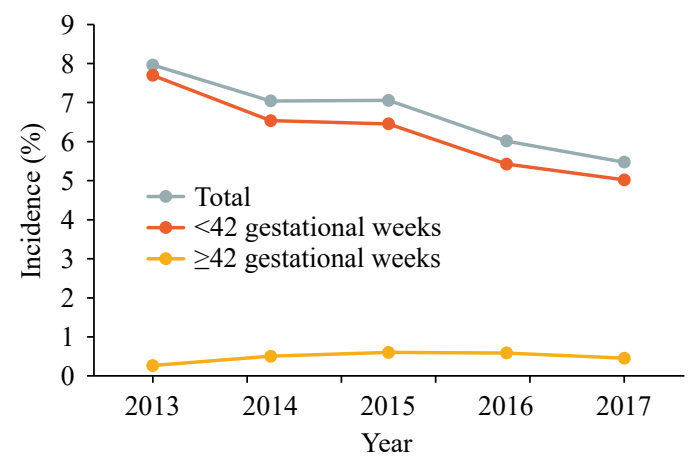

FIGURE 1. Incidence of macrosomia in rural areas of Henan Province from 2013 to 2017.

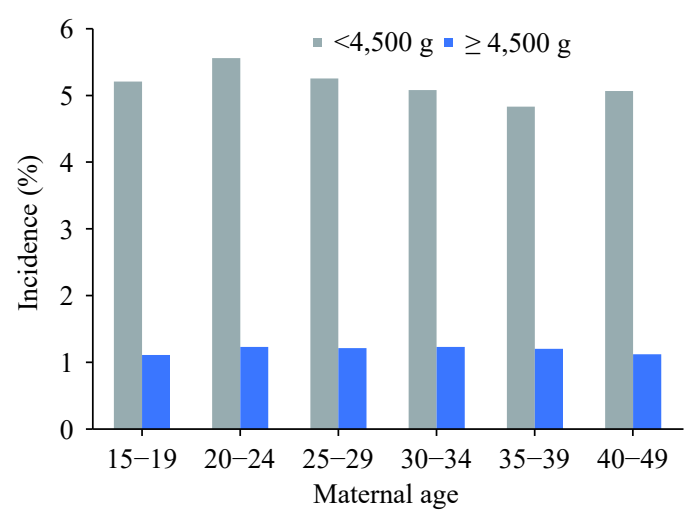

FIGURE 2. Incidence of macrosomia by maternal age in rural areas of Henan Province from 2013-2017.
Figure 3 showed incidence of macrosomia subgroups by maternal education. Significant differences existed across maternal education levels in both macrosomia subgroups. The incidence of macrosomia with $\geq 4,500$ $\mathrm{g}$ subgroup in college and above education group was the highest $(1.55 \%)$, followed by primary and below and senior high school $(1.27 \%$ and $1.26 \%$, respectively), and the lowest incidence was in junior high school $(1.16 \%)\left(\chi^{2}=127.25, P<0.001\right)$. While the incidence of $<4,500 \mathrm{~g}$ subgroup monotonously decreased with declining maternal education level $\left(\chi^{2}=127.25, P<0.001\right.$, respectively).

\section{DISCUSSION}

This study described the distribution characteristics of macrosomia in a large population-based cohort study in rural areas of Henan Province of central China between 2013 and 2017. The total incidence of macrosomia was $6.52 \%$, consistent with results in a population-based survey also in rural areas in two counties in Shanxi $(6.45 \%)$ in 2007-2012 (7) and another sample survey in rural areas of 14 provinciallevel administrative divisions (PLADs) in 2006 (6.3\%) (5). Previous research has reported relatively large variations of macrosomia incidence across regions. For example, a sample survey in 23 PLADs from 2010 to 2014 reported macrosomia's incidence to be $8.7 \%$ (4), yet another survey covering 14 PLADs reported the rate to be $7.3 \%$ in 2011 (3). A regional survey in Foshan City, Guangdong Province reported the incidence at $2.5 \%$ (8), while another survey in Beijing Municipality reported $7.6 \%$ (9). These large disparities

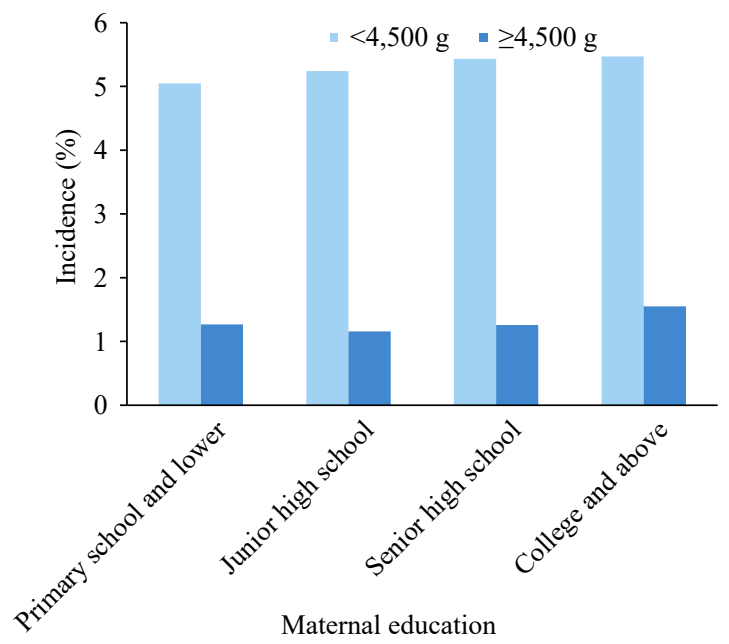

FIGURE 3. Incidence of macrosomia by maternal education in rural areas of Henan Province from 2013-2017. 
in macrosomia incidence could come from "true" differences due to different demographic, socioeconomic, and medical characteristics in different regions and years $(10-11)$, but could also come from different ways and accuracies in estimating gestational age and birth weight, sampling errors, and whether the data were at the hospital or population level.

Our study observed that although there were signs of decrease, the incidence of macrosomia in rural Henan Province was still high. Our previous study indicated the macrosomia comprised $41 \%$ of all adverse pregnancy outcomes ( 7 ). A body of literature has revealed macrosomia to be pertinent to hypertension and metabolic sydrome from childhood to adulthood (1). Gestational weight gain and maternal age are the most crucial drivers of macrosomia (12). With spread of healthcare education, nutrition intervention and weight control for pregnant women, the incidence of macrosomia has been found to reduce in urban areas $(9,13)$, while in rural areas, such healthcare services are less available and the traditional perception of weight gain during pregnancy - "the bigger and heavier, the better" - are still popular. Our study thus suggests the local government and people implement targeted measures to reduce occurrences of macrosomia. For example, education and nutrition consultation should be strengthened among women preparing for pregnancy or who are currently pregnant, especially in rural areas. Besides, local pregnancy nutrition clinics can be established for accurate intervention on gestational weight management.

This study showed disparities in occurrences of macrosomia across different maternal ages and education levels, yet diverse patterns of these disparities were observed in different macrosomia subgroups. Past literature has confirmed an association between macrosomia and maternal sociodemographic factors, but specifics are still unclear as different patterns were observed in different populations (11). Understanding the underlying mechanisms behind relationship between macrosomia and sociodemographic factors would help take targeted measures in different subpopulations.

This study had some strengths. First, the large sample involving more than 1.2 million live births in our study made it possible for us to calculate stable and reliable incidence rate of macrosomia across different sub-populations. Second, as all couples preparing for pregnancy got free check-up in the project, our study was at the population level, thus reducing selection bias.
This study was also subject to some limitations. First, gestational age and birth weight were selfreported by women and thus there might be recall bias. Second, because only those preparing for pregnancy would participate in the Pre-Pregnancy Check-Up Project, our research could not cover unplanned pregnancies. As planned pregnancies have been found to be associated with lower risks of adverse birth outcomes (14), this could partly explain the lower incidence rate in our study.

In conclusion, the present study used a large population-based cohort data to describe the variations of macrosomia incidence in a rural central China PLAD, providing a baseline indication for the researchers and decisionmakers to understand the status of macrosomia. Our findings suggested incidence of macrosomia in Henan Province generally decreased, yet the incidence was still high. Given the short-term and long-term impacts on population quality caused by macrosomia, our study thus calls for maternal healthcare personnel and pregnant women paying attention to nutrition and weight management during pregnancy, especially in rural areas.

Funding: This study was supported by grants from the National Key Research and Development Program of China (2018YFC1004303); National Natural Science Foundation of China (41871360); and the National Health Commission Key Laboratory of Birth Defects and Prevention, Henan Province (ZD202002).

doi: $10.46234 / \mathrm{ccdcw} 2021.196$

\# Corresponding authors: Lijun Pei, peilj@pku.edu.cn; Lifang Jiang, jiangzz66@163.com. ${ }^{1}$ Institute of Population Research/China Center on Population Health
and Development, Peking University, Beijing, China; ${ }^{2}$ National
Health Commission Key Laboratory of Birth Defects Prevention,
Henan Key Laboratory of Population Defects Prevention, Zhengzhou,
Henan, China; ${ }^{3}$ Department of Andrology, Jinling Hospital, School of
Medicine, Nanjing University, Nanjing, Jiangsu, China.

Submitted: August 27, 2021; Accepted: September 07, 2021

\section{REFERENCES}

1. Hermann GM, Dallas LM, Haskell SE, Roghair RD. Neonatal macrosomia is an independent risk factor for adult metabolic syndrome. Neonatology 2010;98(3):238 - 44. http://dx.doi.org/10.1159/0002856 29.

2. Koyanagi A, Zhang J, Dagvadorj A, Hirayama F, Shibuya K, Souza JP, et al. Macrosomia in 23 developing countries: an analysis of a multicountry, facility-based, cross-sectional survey. Lancet 2013;381(9865):476 - 83. http://dx.doi.org/10.1016/s0140-6736(12) 61605-5.

3. Li GH, Kong LJ, Li ZW, Zhang L, Fan L, Zou LY, et al. Prevalence of macrosomia and its risk factors in China: a multicentre survey based on birth data involving 101723 singleton term infants. Paediatr Perinat 
Epidemiol 2014;28(4):345 - 50. http://dx.doi.org/10.1111/ppe.12133.

4. Wang D, Hong Y, Zhu L, Wang XL, Lv Q, Zhou Q, et al. Risk factors and outcomes of macrosomia in China: a multicentric survey based on birth data. J Matern-Fetal Neonatal Med 2017;30(5):623-7. http://dx.doi.org/10.1080/14767058.2016.1252746.

5. Yu DM, Zhai FY, Zhao LY, Liu AD, Yu WT, Jia FM, et al. Incidence of fetal macrosomia and influencing factors in China in 2006. Chin J Child Health Care 2008;16(1):11-3. https://d.wanfangdata.com.cn/ periodical/zgetbjzz200801005. (In Chinese).

6. Liu J, Zhang SK, Liu M, Wang QM, Shen HP, Zhang YP. Maternal pre-pregnancy infection with hepatitis $\mathrm{B}$ virus and the risk of preterm birth: a population-based cohort study. Lancet Glob Health 2017; 5(6):e624 - 32. http://dx.doi.org/10.1016/S2214-109X(17)30142-0.

7. Lin SQ, Zhang Y, Li JJ, Wu JL, Pei LJ. Trends of adverse pregnancy outcomes in a high prevalence region of birth defects - Shanxi province, China, 2007-2019. China CDC Wkly 2021;3(31):661 - 4 . http://dx.doi.org/10.46234/ccdcw2021.167.

8. Rao JM, Fan DZ, Wu SZ, Lin DX, Zhang HS, Ye SX, et al. Trend and risk factors of low birth weight and macrosomia in south China, 20052017: a retrospective observational study. Sci Rep 2018;8(1):3393. http://dx.doi.org/10.1038/s41598-018-21771-6.

9. Shan XY, Chen FF, Wang WP, Zhao J, Teng Y, Wu MH, et al. Secular trends of low birthweight and macrosomia and related maternal factors in Beijing, China: a longitudinal trend analysis. BMC Pregnancy Childbirth 2014;14:105. http://dx.doi.org/10.1186/1471-2393-14105.

10. Zhang XL, Xu HF, Hu R, Xiong Y, Gu WR, Zhou QJ, et al. Changing trends of adverse pregnancy outcomes with maternal age in primipara with singleton birth: a join point analysis of a multicenter historical cohort study in China in 2011-2012. Acta Obstet Gynecol Scand 2019;98(8):997 - 1003. http://dx.doi.org/10.1111/aogs.13595.

11. Ruiz M, Goldblatt P, Morrison J, Kukla L, Švancara J, Riitta-Järvelin $\mathrm{M}$, et al. Mother's education and the risk of preterm and small for gestational age birth: a DRIVERS meta-analysis of 12 European cohorts. J Epidemiol Community Health 2015;69(9):826 - 33 . http://dx.doi.org/10.1136/jech-2014-205387.

12. Lu YY, Zhang J, Lu XR, Xi W, Li Z. Secular trends of macrosomia in southeast China, 1994-2005. BMC Public Health 2011;11:818. http://dx.doi.org/10.1186/1471-2458-11-818.

13. Zhao NX, Yang HX. Influence of maternal obesity and excessive weight gain during pregnancy on perinatal outcome and long term health in offspring: a review. Chin J Perinat Med 2020;23(9):640 - 4.

14. Flower A, Shawe J, Stephenson J, Doyle P. Pregnancy planning, smoking behaviour during pregnancy, and neonatal outcome: UK millennium cohort study. BMC Pregnancy Childbirth 2013;13:238. http://dx.doi.org/10.1186/1471-2393-13-238. 